\title{
Relationship of organizational culture, teamwork and job satisfaction in interprofessional teams
}

\author{
Mirjam Körner ${ }^{1 *}$, Markus A. Wirtz ${ }^{2}$, Jürgen Bengel ${ }^{3}$ and Anja S. Göritz ${ }^{4}$
}

\begin{abstract}
Background: Team effectiveness is often explained on the basis of input-process-output (IPO) models. According to these models a relationship between organizational culture (input $=1$ ), interprofessional teamwork (process $=P$ ) and job satisfaction (output $=0$ ) is postulated. The aim of this study was to examine the relationship between these three aspects using structural analysis.

Methods: A multi-center cross-sectional study with a survey of 272 employees was conducted in fifteen rehabilitation clinics with different indication fields in Germany. Structural equation modeling (SEM) was carried out using AMOS software version 20.0 (maximum-likelihood method).

Results: Of 661 questionnaires sent out to members of the health care teams in the medical rehabilitation clinics, 275 were returned (41.6\%). Three questionnaires were excluded (missing data greater than $30 \%$ ), yielding a total of 272 employees that could be analyzed. The confirmatory models were supported by the data. The results showed that $35 \%$ of job satisfaction is predicted by a structural equation model that includes both organizational culture and teamwork. The comparison of this predictive IPO model (organizational culture (I), interprofessional teamwork $(P)$, job satisfaction $(O)$ ) and the predictive IO model (organizational culture (I), job satisfaction (O)) showed that the effect of organizational culture is completely mediated by interprofessional teamwork. The global fit indices are a little better for the IO model (TLI: .967, CFI: .972, RMSEA .052) than for the IPO model (TLI: .934, CFI: .943, RMSEA: .61), but the prediction of job satisfaction is better in the IPO model $\left(R^{2}=35 \%\right)$ than in the 10 model $\left(R^{2}=24 \%\right)$.

Conclusions: Our study results underpin the importance of interprofessional teamwork in health care organizations. To enhance interprofessional teamwork, team interventions can be recommended and should be supported. Further studies investigating the organizational culture and its impact on interprofessional teamwork and team effectiveness in health care are important.
\end{abstract}

Keywords: Organizational culture, Teamwork, Job satisfaction, Hospital, Health care

\section{Background}

Patients with chronic diseases have complex health needs and typically require treatment by more than one health care discipline [1]. In Germany, chronic care is provided in in-patient facilities ("rehabilitation clinics") with interprofessional teams [2]. These teams consist of professionals of at least two health care disciplines who work together toward a common goal to achieve an optimal outcome for their patients [3-6]. Usually, the

\footnotetext{
* Correspondence: mirjam.koerner@mps.uni-freiburg.de

${ }^{1}$ Medical Psychology and Medical Sociology, University of Freiburg, Hebelstr. 29, 79104 Freiburg, Germany

Full list of author information is available at the end of the article
}

teams comprise physicians, nurses, physiotherapists, sport therapists, psychotherapists, psychologists, social workers, and dieticians [6-8], with the particular team composition depending on the type of chronic diseases treated in the clinic.

Team effectiveness is often explained on the basis of input-process-output models (IPO) [7, 9-16]. IPO models describe the impact of input (e.g., organizational culture, team composition, structure of communication, task design) and the mediating process (e.g., communication, coordination, respect, conflict leadership) on team output (e.g., team performance, job satisfaction, well-being, cost effectiveness, quality of care, treatment

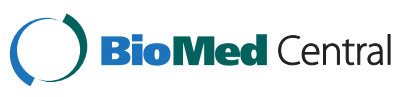


outcome) $[11,12,14]$. IPO models are heterogeneous with regard to their complexity and the elements they include. To empirically examine an IPO model, researchers typically select several elements in the models [17-20].

Organizational characteristics, such as organizational culture, are important aspects for interprofessional teamwork, treatment quality and success [21, 22]. Studies have demonstrated that interprofessional teamwork is influenced by organizational culture [23, 24]. Further studies have shown that teamwork predicts job satisfaction [14, 25-28]. However, until now no study has investigated a single model which includes all of the constructs in one model. This means, in detail, organizational culture as input, interprofessional teamwork as process, and job satisfaction as output, as well as the mediating effect of interprofessional teamwork in health care.

\section{Organizational culture}

Organizational culture is often considered as the precondition of teamwork in the organization. It is defined as the shared values, beliefs, or perceptions held by employees within an organization [29], and "is the social glue holding an organization together" ([30], p. 2). Schein [31] stated that organizational culture consists of the underlying assumptions and beliefs that the members of an organization share and that operate unconsciously. Mission, strategy, structure, leadership and human resource practices are important determinants of organizational culture [32]. An organization with a strong culture helps employees to accomplish their goals and tasks and be satisfied in their job [30]. Organizational culture is "an important explanatory variable for behavior and performance in the workplace" ([32], p. 116) and influences teamwork and treatment outcomes [32]. Moreover, organizational culture predicts job satisfaction [30, 33-35]. Existing studies focus on the impact of organizational culture on implementing interventions [36], quality improvement [37], patient safety [38], or performance $[39,40]$, or focus only on one professional group such as nurses (e.g. [41, 30]). Additionally, these studies were conducted in acute care centers or nursing homes. Only Strasser [32] performed a study in the interprofessional rehabilitation setting. They verified that team functioning differs significantly depending on the dominant organizational culture. The highest team functioning scores were achieved by teams with a more personal and dynamic organizational culture rather than those that were more bureaucratic and formal [32]. Organizational culture influences the implementation of interventions in health care organizations, therefore its characteristics need to be investigated in order to improve implementation processes, e.g. for guidelines [42]. There are only a few questionnaires for organizational culture which are clinic-specific (e.g. Hospital Culture Questionnaire [43], The Hospital Culture Scale [44]), or used in a clinical setting [45]. All of them have limitations concerning their psychometrical testing, structure and theoretical basis and vary in their definition of organizational culture [45].

\section{Interprofessional teamwork}

Interprofessional teamwork is a key feature of the comprehensive chronic care approach [46-48]. It is defined as a partnership "in a participatory, collaborative and coordinated approach to shared decision-making around health and social issues" of the patients ([5], p. 11). Körner and Wirtz [49] define the core dimensions of client-centered interprofessional teamwork as communication, cooperation, coordination, respect, and work climate. Furthermore, teamwork in health care may be categorized into interprofessional versus multiprofessional team approaches $[12,28]$. The two approaches differ in organization, leadership, communication and decisionmaking, with the interprofessional approach achieving better results in teamwork and higher staff satisfaction than the multiprofessional approach [28]. Multiprofessional teamwork means that the different disciplines/professions work separately, each with its own treatment goals. The physician determines and delegates the treatment options to the other health care professionals in a one-way, mostly bilateral interaction process between the professionals. In contrast, the interprofessional approach is more interactive and participative, with the health care professionals agreeing on a common treatment goal and adapting their discipline-specific goals to this common goal. The physician involves the other health care professionals in treatment decisions within a multilateral interaction process and coordinates the treatment in interprofessional team meetings $[28,50]$. Several studies have shown the effects of interprofessional teamwork on outcome criteria on the client, staff and organization level: On the client/patient level, high quality teamwork is linked with higher satisfaction and treatment acceptance [51], improved quality of treatment [52], improved patient safety $[53,54]$ and better clinical outcomes $[14,16]$. On the staff level, higher job satisfaction [28], greater well-being [55], improved mental health, better team climate and increased team efficiency [56] have been reported. On the organization level, high quality teamwork is associated with cost savings, higher workforce retention and reduced turnover $[16,57]$.

\section{Job satisfaction}

Job satisfaction is a main outcome criterion in the IPO models for staff [58] and an extensively researched work attitude in organizational psychology [59]. The most widely accepted definition of job satisfaction has been formulated by Locke [60], who defined job satisfaction as "a pleasurable or positive emotional state resulting from the appraisal of one's job or job experiences" ([60], p. 1304). It can be measured with one global item, which 
refers to employees' overall attitude towards their jobs. Job satisfaction is often used to operationalize team success $[12,61,62]$. However, there are also assessments that divide job satisfaction into different dimensions [63]. This is due to the impact of job satisfaction on the perception of quality of care and patient outcomes, such as length of hospital stay, medical errors and mortality $[26,52,64]$, and its association with performance, motivation, absenteeism/tardiness, mental/physical health and general life satisfaction [65].

\section{The present study}

Few studies have tested the mediating effects of team process variables based on the IPO model [66]. To the best of our knowledge, no study has combined organizational culture, interprofessional teamwork and job satisfaction. We developed our model (see Fig. 1) using the IPO model $[11,12,14,15]$ as a framework and considering the abovementioned research on teamwork and the impact of organizational culture on job satisfaction. Based on previous findings [30, 33-35], we also tested whether job satisfaction can be predicted through interprofessional teamwork. Moreover, we do not limit our study to one professional group, such as nurses or physicians, as practiced in most other studies, but include all kinds of different health care professionals, because interprofessional teamwork is perceived as a key feature of the comprehensive chronic care approach in rehabilitation in Germany $[24,46,48,67,68]$.

The aim of this study was to examine the model (see Fig. 1) using structural analysis. In particular, we sought to empirically (a) assess model variables and (b) estimate the associations and predictive relationships between organizational culture, interprofessional teamwork and job satisfaction as illustrated in Fig. 1, as well as the direct association of organizational culture with job satisfaction. To this end, the following hypotheses were formulated regarding the fit of the model and the relationships within the models.
Hypothesis 1: The data can be adequately modeled by a theory-based structural equation model.

Hypothesis 2:

a) Interprofessional teamwork mediates between organizational culture and job satisfaction.

b) Organizational culture is also an independent predictor of job satisfaction.

\section{Method}

This multi-center cross-sectional study was part of the project "Development and evaluation of a shareddecision-making training program in medical rehabilitation" funded by the German Federal Ministry of Research and Education and the German Statutory Pension Insurance Scheme (Grant 01GX0720). For this study, we collected data at fifteen rehabilitation clinics that treated different chronic diseases using an employee survey, which measured an individual health care professional's perspective. Six of the centers were psychosomatic clinics and nine were somatic rehabilitation clinics with a wide range of indications (i.e., orthopedics, cardiology, neurology, oncology, metabolism and pulmonology). Each clinic designated a contact person (typically a senior physician or psychologist) who was responsible for the implementation of the study: All questionnaires $(\mathrm{N}=662)$ were sent to these contact persons, who distributed them to all health care professionals at their clinic. Two weeks after the deadline, we sent out reminders to all health care professionals.

The study included all health care professionals who worked within a team and were directly involved in patient treatment. It was conducted in accordance with the Declaration of Helsinki [69]. All ethical principles for medical research involving human subjects were approved and supported by the Ethics Committee of the University of Freiburg.

\section{Instruments}

For the assessment of organizational culture, a Hospital Culture Questionnaire (HCQ) was developed based on

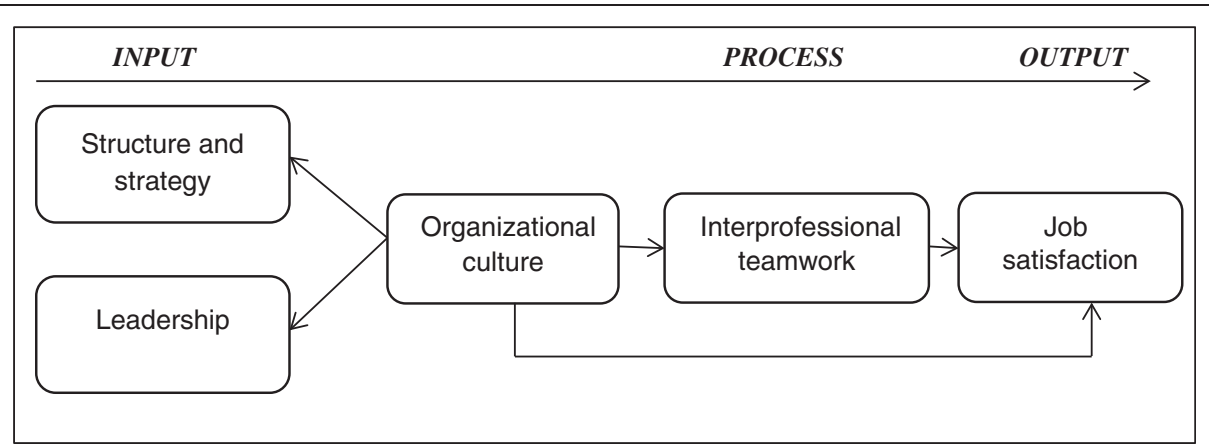

Fig. 1 Model of the impact of organizational culture on teamwork and job satisfaction (IPO model) 
the Corporate Culture Scale-Short Form (CCS-SF) by Jöns [70], because there was no German questionnaire for this construct. The adaption for the clinical context takes place in a consensus process of three experts of different health care professions (psychologist, physician and physiotherapist). Since most of the original items fitted the clinical context, we only had to adapt the wording in some parts, e.g. clinic instead of company or patient instead of customer. We also omitted two items (the relationship of the staff is characterized/shaped by cooperation and the trust of the staff in their leaders is high) on the assumption that the team-orientated clinic includes this, and added a further three (conflict management, control of difficult situations, and ability to criticize in a constructive way) on the basis of a pilot study. Likewise, staff-centeredness is included as an important quality criterion for health care organizations [71]. The bipolar scaling of the CCS-SF has been simplified in a unipolar scale. This newly developed Hospital Culture Questionnaire consists of 14 items: six for "structure and strategy" and eight for "leadership" (see Additional file 1). The 14 items were assessed on a five-point Likert-Scale $(1=$ strongly agree to $5=$ strongly disagree), and there was also the option of checking "no opinion". The values of the items were recoded $(1=$ strongly disagree and $5=$ strongly agree) before calculating the scores of the subscales Structure and Strategy and Leadership and the complete scale Organizational culture, because we wanted higher values to indicate a more favorable evaluation. Patient-centeredness, staff, team and quality orientation, decision-making and openness for innovations are the main topics of the items on the Structure and strategy subscale. A sample item is "in my view the clinic is quality-oriented." The leadership subscale captures leadership performance, and the items focus on trust, cooperation, difficult situations, conflict management, constructive criticism, participation, information and relevance of teamwork. The complete scale Organizational culture consists of both subscales. The HCQ was psychometrically tested and validated [72]. Scale reliability was checked by computing Cronbach's alpha (Structure and strategy: .85 and Leadership: .92) [72]. The two scales correlate highly $(\mathrm{r}=.52-.62)$ with scales which are similar in content (e.g. leadership, organization and communication and organizational climate).

Teamwork was measured using the Internal Participation Scale (IPS) [49] which captures the core dimensions of teamwork identified by Valentine, Nembhard and Edmondson [73]. The items capture communication ("Communication in the team is efficient") and cooperation among health care professionals ("The health care professionals work hand-in-hand"), coordination of treatment options within the interprofessional team ("The different types of treatment are well coordinated"), coordination of the health care professionals ("Agreements among health care professionals are well coordinated"), respect among the health care professionals ("The health care professionals respect each other") and climate within the interprofessional team ("Overall there is a friendly climate in the clinic"). The six IPS items are assessed on a four-point Likert scale ( $1=$ does not apply at all, 2 = generally does not apply, $3=$ generally applies, 4 = fully applies), with the additional option of responding "I cannot judge this." When calculating the total score (team score), one missing item is accepted. The raw scores are transformed to a range from 0 (minimum level of teamwork) to 100 (highest level of teamwork). The IPS possesses good psychometric properties [49].

Job satisfaction was measured using the item "How satisfied are you in general with your job?" from the Questionnaire on Staff Satisfaction in Medical Rehabilitation by Farin et al. [74], which is assessed on a fivepoint Likert scale $(1=$ very dissatisfied, $2=$ dissatisfied, $3=$ neither satisfied nor dissatisfied, $4=$ satisfied, $5=$ very satisfied). The psychometric criteria of this item were proved to be good.

\section{Statistical analysis}

Initially, the items were checked for plausibility, and missing data analysis was performed. Descriptive statistics were calculated using SPSS version 20.0. Structural equation modeling (SEM) was carried out using AMOS software version 20.0 (maximum-likelihood method). Data was imputed by means of the expectation-maximum algorithm to avoid biases, even in cases of missing at random (MAR) [75]. Structural equation modeling (SEM) was conducted to verify whether the proposed model reproduced the data. Several global fit measures were considered. Chi-square $\left(X^{2}\right)$, the Comparative Fit Index (CFI), the Tucker-Lewis Index (TLI) and the Root Mean Square Error of Approximation (RMSEA) were used as goodnessof-fit indicators. The $X^{2}$-test was used as the strictest form of model testing [76]. In addition, the TLI and the CFI were calculated as measures of incremental model fit. For these measures, values $\geq .90$ are suggested as criteria for an acceptable model fit and $\geq .95$ for a good fit [77, 78]. The RMSEA indicates the proportion of variancecovariance information not correctly predicted by the model. Values of $\leq .08$ or $\leq .05$ are deemed to indicate an acceptable or good fit, respectively [77]. Furthermore, indicators of local fit were applied. The proportion of variance of the indicators (IR) predicted by the construct is supposed to amount to $>.40$, and the average proportion of variance (AVE) measured by the construct is supposed to be $>.50$ [76]. As criterion for factor reliability (FR), values $>.60$ are accepted as satisfactory [79]. The discriminant validity was checked using the Fornell-Larcker 
criterion, which requires the construct to be more strongly related to its own indicators than to other model constructs [78].

\section{Participants}

Of 661 questionnaires sent out to members of the health care teams in the medical rehabilitation clinics, 275 were returned (41.6\%). Three questionnaires (staff members) were excluded because too much information was missing (more than $30 \%$ ), yielding a total of 272 employees that could be analyzed. Most of the items have zero to four responses with missing data ( $\mathrm{n}=15$ items). Only five items have seven and more, with the maximum number at $17(6.3 \%)$ for the IPS item "The different types of treatment are well coordinated".

Table 1 displays the sample characteristics. About one fourth of the participants were psychosocial therapists, and about $18 \%$ physicians, nursing staff and physical therapists (physiotherapists and sport teachers). Most of the health care professionals were aged between 26 and 55 , worked full time and had worked for more than five years at their clinic.

\section{Results}

The descriptive statistics pertaining to all scales are summarized in Table 2. The mean values $(\mathrm{M})$ for all scales were neutral to positive $(M \geq 3)$, and standard deviations (SD) ranged between .53 and .87. Although there are significant violations of symmetry for the three scales Structure and strategy, Teamwork and Job satisfaction, the absolute skewness (values below 3) can be considered acceptable [76, 80]. Specifically, these three scales are left-skewed (see t-value in Table 2), but without significant ceiling effects. According to Kline [81], absolute skewness values below 3 indicate no critical violation of the normal distribution assumption.

The two subscales Structure and strategy and Leadership link highly with one another, and as expected, they have a high association with the complete scale Organizational culture. There are also high correlations between Teamwork and Organizational culture and its two subscales. The associations of all these scales with Job satisfaction are moderate (see Table 3).

\section{Structural equation analysis}

A three-factor measurement model (Structure and strategy, Leadership and Teamwork) with a total of 20 items was used as a basis to confirm the model. The global model fit indices (see Table 4) illustrate that this original confirmatory model (model 1) explained the data acceptably $\left(X^{2} / \mathrm{df}>2\right.$, TLI $<.95$, CFI $<.95$ and RMSEA $\left.<.05\right)$. The items patient oriented and agreements have indicator reliabilities lower than .4 (see Table 4), but were not eliminated to maintain the complete scale in the
Table 1 Description of sample $(n=272)$

\begin{tabular}{|c|c|c|}
\hline & Frequency & Percent \\
\hline \multicolumn{3}{|l|}{ Gender } \\
\hline Male & 94 & 34.6 \\
\hline Female & 164 & 60.3 \\
\hline Missing & 14 & 5.1 \\
\hline \multicolumn{3}{|l|}{ Age Groups } \\
\hline $17-25$ & 12 & 4.4 \\
\hline $26-35$ & 40 & 14.7 \\
\hline $36-45$ & 82 & 30.1 \\
\hline $46-55$ & 88 & 32.4 \\
\hline $56-65$ & 38 & 14.0 \\
\hline Missing & 12 & 4.4 \\
\hline \multicolumn{3}{|l|}{ Professionals } \\
\hline Physicians & 49 & 18.0 \\
\hline Nursing staff & 48 & 17.7 \\
\hline Psychosocial therapists & 67 & 24.6 \\
\hline Physical therapists & 50 & 18.4 \\
\hline Others & 37 & 13.6 \\
\hline More than one professional group & 12 & 4.4 \\
\hline Missing & 9 & 3.3 \\
\hline \multicolumn{3}{|l|}{ Job tenure } \\
\hline More than one year, but less than three years & 37 & 13.6 \\
\hline Three to five years & 26 & 9.6 \\
\hline More than five years & 190 & 69.9 \\
\hline Less than one year & 13 & 4.8 \\
\hline Missing & 6 & 2.2 \\
\hline \multicolumn{3}{|l|}{ Employment } \\
\hline Full-time & 174 & 64.0 \\
\hline Part-time (more than $70 \%$ but less than $100 \%$ ) & 41 & 18.0 \\
\hline Part-time (more than $30 \%$ but less than $70 \%$ ) & 35 & 15.1 \\
\hline Missing & 14 & 2.9 \\
\hline
\end{tabular}

analysis. Furthermore, the substantial error correlations (covariance modification indices (M.I.)) indicate local dependency between the items participatory leadership style and trust in employees (M.I.: 30.19), between cooperation and agreements (M.I.: 21.18) as well as between respect and communication (M.I.: 27.14), and they were

Table 2 Descriptive statistics for all variables of the model

\begin{tabular}{lccccc}
\hline Factor & Scale range & $\mathrm{M}$ & $\mathrm{SD}$ & Skewness & $\mathrm{t}$ \\
\hline Structure and strategy & $1-5$ & 3.39 & .82 & -.37 & -2.46 \\
Leadership & $1-5$ & 3.10 & .87 & -.07 & -0.43 \\
Organizational culture & $1-5$ & 3.23 & .81 & -.20 & -1.33 \\
Interprofessional teamwork & $1-4$ & 2.95 & .53 & -.63 & -4.52 \\
Job satisfaction & $1-5$ & 3.91 & .83 & -.10 & -6.74
\end{tabular}

Higher values indicate a more favorable rating 
Table 3 Product-moment correlations among all scales and subscales

\begin{tabular}{|c|c|c|c|c|c|}
\hline Factor & Structure and strategy & Leadership & Organizational culture & Interprofessional teamwork & Job satisfaction \\
\hline Structure and strategy & 1 & $.78^{* *}$ & $.92^{* *}$ & $.59 * *$ & $.44^{* *}$ \\
\hline Leadership & & 1 & $.96^{* *}$ & $.65^{* *}$ & $.43^{* *}$ \\
\hline Organizational culture & & & 1 & $.66^{* *}$ & $.46^{* *}$ \\
\hline Interprofessional teamwork & & & & 1 & $.44^{* *}$ \\
\hline Job satisfaction & & & & & 1 \\
\hline
\end{tabular}

** $\mathrm{p}<.01$

taken into account in a modified confirmatory model (model 2). With model 2, an acceptable to good fit was achieved for all fit indices $\left(X^{2} / \mathrm{df}=2, \mathrm{TLI}=.94, \mathrm{CFI}=.95\right.$ and RMSEA <.06). The local fit indices for model 2 are summarized in Table 5. The required thresholds for factor reliability in structural equation models $(\geq .6)$ and average variance explained $(\geq .5)$ have been exceeded for all scales. The threshold for indicator reliability was exceeded in 18 out of 20 items. The t-values of all factor loadings were significant.

The high correlation between the two latent factors structure and strategy and leadership (.90) support the factor of a second-order organizational culture as theoretically assumed. Next, with the predictive models we took the modified confirmatory model (model 2) as the base and added this second-order factor as well as job satisfaction as criteria (model 3: IPO and model 4: IO). Good model fit proved to be stable for these prediction models (see Table 4). The first predictive model (model 3: IPO) has a better fit than model 2 (confirmatory model with second-order factor), rendering the global fit acceptable to good. Model 3 predicts $35 \%$ of job satisfaction (see Fig. 2). Thereby - as expected - the association between each of the two subscales, structure and strategy and leadership, and the complete scale, organizational culture, is significant $\left(\beta_{\text {leadership }}=.99\right.$ and $\left.\beta_{\text {structure and strategy }}=.80, \mathrm{p}<.001\right)$. Interprofessional teamwork is a significant predictor of job satisfaction (standardized regression weight: $\beta=.80 ; \mathrm{p}<.001$ ), but organizational culture is not $(\beta=-.033 ; \mathrm{p}=.57)$. Next, when removing interprofessional teamwork with its six items from the IPO model, organizational culture becomes a significant predictor of job satisfaction $(\beta=.47$, $\mathrm{p}<.001)$. The fit of the IO model improved compared to model $3\left(X^{2} / \mathrm{df}=1.72 \quad \mathrm{TLI}=97, \quad \mathrm{CFI}=.97\right.$ and RMSEA = .5). However, the explained variance in job satisfaction decreased to $24 \%\left(\mathrm{R}^{2}\right)$ (see Table 4 and Fig. 3). All latent factors can be delimited from one another to a sufficient degree, as the correlations are always lower than the square root of average variance extracted (Fornell-Larcker criterion, [78, 82]).

\section{Discussion}

Based on the IPO model [11, 12, 14, 15] and empirical findings on the influence of organizational culture $[30,33,34]$ and interprofessional teamwork [27, 28] on job satisfaction, a theoretical model was developed that defines organizational culture as an input variable, interprofessional teamwork as a process variable and job satisfaction as the output variable. The confirmatory models (model 1 and model 2) were supported by the data (Hypothesis 1). Furthermore, the results showed that $35 \%$ of job satisfaction is predicted by a structural equation model that includes both organizational culture and Interprofessional teamwork (Hypothesis 2a). The comparison of model 3 (IPO: organizational culture - interprofessional teamwork -

Table 4 Global model fit indices for all estimated models

\begin{tabular}{|c|c|c|c|c|c|c|c|}
\hline & $x^{2}$ & $d f$ & $\mathrm{p}$ & $x^{2} / \mathrm{df}$ & TLI & $\mathrm{CFI}$ & RMSEA I \\
\hline Threshold for acceptable fit & - & - & $<.05$ & $\leq 2.5$ & $\geq .90$ & $\geq .90$ & $\leq .08$ \\
\hline good fit & - & - & - & $\leq 2.0$ & $\geq .95$ & $\geq .95$ & $\leq .05$ \\
\hline Confirmatory models & - & - & - & - & - & - & - \\
\hline Model 1 (original confirmatory model) & 406.08 & 167 & $<.001$ & 2.43 & .914 & .924 & {$\left[\begin{array}{lll}.064 & .073 .082\end{array}\right]$} \\
\hline Model 2 (modified confirmatory model) & 324.24 & 164 & $<.001$ & 1.98 & .941 & .949 & {$\left[\begin{array}{lll}.050 & .060 & .070\end{array}\right]$} \\
\hline Predictive models & - & - & - & - & - & - & - \\
\hline Model 3 (IPO model) & 370.80 & 184 & $<.001$ & 2.02 & .934 & .943 & {$\left[\begin{array}{lll}.052 & .061 & .070\end{array}\right]$} \\
\hline Model 4 (IO model) & 156.06 & 88 & $<.001$ & 1.72 & .967 & .972 & {$\left[\begin{array}{lll}.037 & .052 & .065\end{array}\right]$} \\
\hline
\end{tabular}

I, Input (organizational culture)

$P$, Process (interprofessional teamwork)

$O$, Output (job satisfaction) 
Table 5 Measures of local fit for modified confirmatory model

\begin{tabular}{|c|c|c|c|c|c|}
\hline Scales & Items & $\mathrm{IR}$ & $C R$ & $\mathrm{FR}$ & AVE \\
\hline Threshold for acceptable fit & & $\geq .4$ & $\mid$ C.R. $\mid>2, p<.05$ & $\geq .6$ & $\geq .5$ \\
\hline \multirow[t]{6}{*}{ Structure and strategy } & 1 Patient oriented & .34 & - & & \\
\hline & 2 Staff oriented & .66 & $9.83^{* * *}$ & & \\
\hline & 3 Quality oriented & .51 & $9.10^{* * *}$ & .85 & .50 \\
\hline & 4 Open for innovations & .48 & $8.93^{* * *}$ & & \\
\hline & 5 Team oriented & .66 & $9.82^{* * *}$ & & \\
\hline & 6 Quick decision-making & .29 & $7.46^{* * *}$ & & \\
\hline \multirow[t]{8}{*}{ Leadership } & 7 Participatory leadership style & .62 & $13.73^{* * *}$ & & \\
\hline & 8 Trust in employees & .46 & $12.34^{* * *}$ & & \\
\hline & 9 Valuing internal communication & .59 & $13.38^{* * *}$ & & \\
\hline & 10 Staff participation & .65 & $14.19^{* * *}$ & & \\
\hline & 11 Open conflict management & .54 & $12.70^{* * *}$ & .92 & .58 \\
\hline & 12 Appreciation of interprofessional teamwork & .53 & $12.52^{* * *}$ & & \\
\hline & 13 Managing difficult situations with employees & .59 & - & & \\
\hline & 14 Constructive criticism & .65 & $14.16^{* * *}$ & & \\
\hline \multirow[t]{6}{*}{ Interprofessional teamwork } & 15 Climate & .62 & - & & \\
\hline & 16 Cooperation & .58 & $12.34^{* * *}$ & & \\
\hline & 17 Coordination & .47 & $10.89^{* * *}$ & .85 & .50 \\
\hline & 18 Agreements & .29 & $8.57^{* * *}$ & & \\
\hline & 19 Respect & .50 & $11.35^{* *}$ & & \\
\hline & 20 Communication & .51 & $11.58^{* * *}$ & & \\
\hline
\end{tabular}

$I R$, Indicator reliability; $C R$, Critical ratio; $F R$, Factor reliability; AVE, Average variance extracted

${ }^{* * *} \mathrm{p}<.001,{ }^{* *} \mathrm{p}<.01$

job satisfaction) and model 4 (IO: organizational culture - job satisfaction) showed that the effect of organizational culture is completely mediated by interprofessional teamwork. The global fit indices are a little better for model 4 (TLI: .967, CFI: .972, RMSEA .052) than for model 3 (TLI: .934, CFI: .943, RMSEA: .61), but the prediction of job satisfaction is better in the IPO model (model 3) $\left(R^{2}=35 \%\right)$ than in the IO model (model 4$)\left(R^{2}=24 \%\right)$.
The IO model supports Hypothesis $2 \mathrm{~b}$, which postulated that organizational culture predicts job satisfaction independently [30, 33-35]. However, if we include interprofessional teamwork (model 3), organizational culture loses its predictive value for job satisfaction, and interprofessional teamwork mediates the relationship between these two constructs completely. Few studies have explicitly investigated the mediator effect of teamwork based on

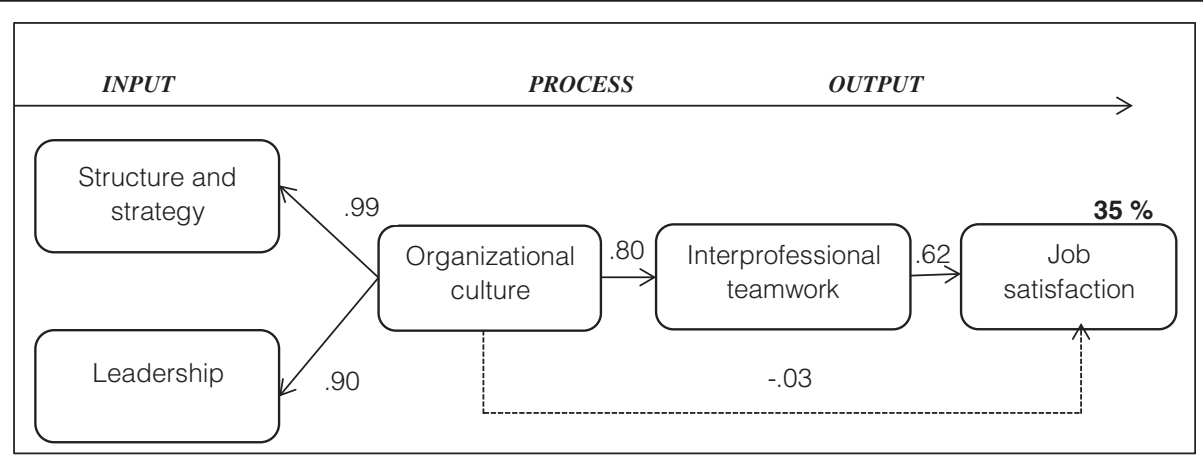

Fig. 2 Structural equation IPO model for the prediction of job satisfaction (Model 3). The figures on the paths are the standardized path coefficients. To ensure identifiability, the indicator paths leadership and structure and strategy were fixed to 1 


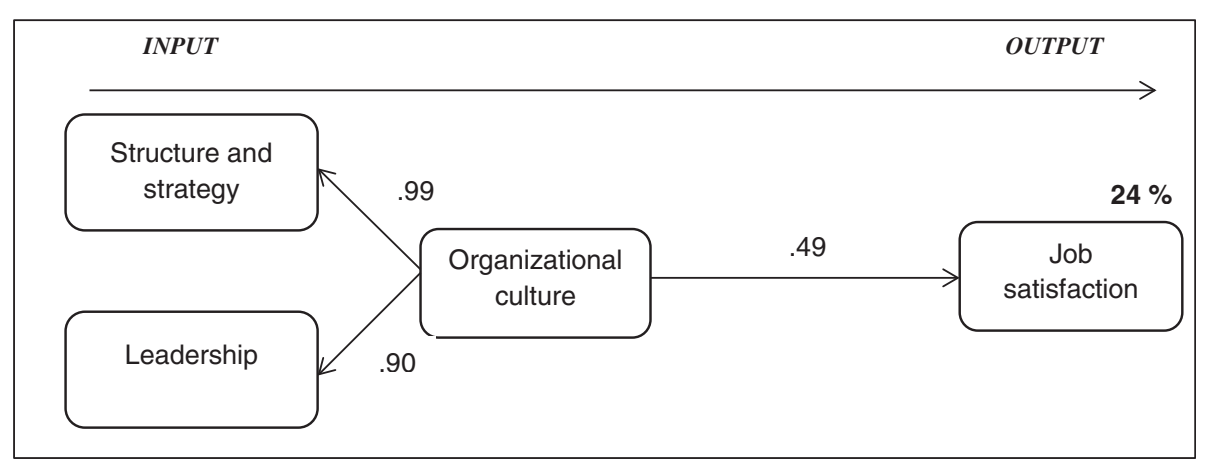

Fig. 3 Structural equation IO model for the prediction of job satisfaction (Model 4). The figures on the paths are the standardized path coefficients. To ensure identifiability, the indicator paths structure and strategy and leadership were restricted (leadership = 1 and structure and strategy $=.7)$

the IPO model [83-85], and they were not performed in the health care setting. Most of the health care studies show the single influences of organizational culture on teamwork [23, 24, 32] or teamwork on job satisfaction [25-28] or organizational culture on job satisfaction [30,33,35], but there is no comparable study in health care which considers all three constructs together. Tsai [30] showed the relationships between organizational culture, leadership behavior and job satisfaction. We used leadership as a dimension of organizational culture and not as a separate construct. We also retrieved a high correlation of the constructs in our study and solved this by using "organizational culture" as a higher level factor. Leadership style is important for organizational culture as well as for interprofessional teamwork [45]. Schein [86] emphasized that culture and leadership style are "two sides of the same coin" [p. 28], since executives create culture and are influenced by it. Further findings [30, 33, 87] to the association of organizational culture and job satisfaction are also consistent with our IO model.

Furthermore Chang et al. [26] showed that interprofessional teamwork was one of the most important predictors of job satisfaction as stated in the IPO models [14, 88]. Taking the IPO model $[11,12,14,15]$ as a framework and using organizational culture as an input variable, we find a complete mediation of the effect of organizational culture on job satisfaction through teamwork. In other words, organizational culture affects job satisfaction presumably through the intermediate process - interprofessional teamwork. Thus it could be assumed that it is most important to establish good interprofessional teamwork in order to increase job satisfaction in health care. In line with previous study findings $[28,52,88-90]$, this stresses the importance of high quality interprofessional teamwork in health care. From a practical point of view, these findings provide essential clues for enhancing interprofessional teamwork and ensuring high job satisfaction. There are several interventions available for improving interprofessional teamwork [12, 52, 91, 92], but there are only a few studies on this issue [93].

A limitation of this finding is the overlapping of the constructs of interprofessional teamwork and organizational culture. Theoretically, the constructs cannot be differentiated precisely; for example, teamwork is used as a dimension of organizational culture [45], or leadership (in our study, a scale of organizational culture) is also a dimension of teamwork and climate (in this study, an item of teamwork, IPS) is highly associated with culture [70]. Empirically, there is also a high correlation between organizational culture and teamwork $(r=.66)$. Strasser et al. [32] also find associations between types of organizational culture and teamwork. The highest team functioning scores were found in teams with a dynamic culture and the lowest scores in a formalized and structured culture. Organizational culture can support teamwork [32, 94, 95]. This leads us to the conclusion that both aspects - interprofessional teamwork and organizational culture - are equally important for job satisfaction. Concerning organizational culture, the leadership is supposed to be the most important characteristic [40, 45]. "It was found that encouragement and support by leaders, their trust and clear vision, their consistent behavior in this regard and their ability to convince subordinates to acknowledge their vision can all influence employee job satisfaction." ([30], p. 105).

The problem of overlapping can also be found in the conceptualization of IPO models, where team aspects often cannot be clearly categorized as input or process (e.g. in some models leadership is used as an input variable and in others as a process variable). It can be assumed that there are interaction effects between input and process variables [96]. In our case, the IPO models only consider a linear path from organizational culture to interprofessional teamwork, but there could also be feedback loops or effects the other way around [97]. For example, 
Aydin and Ceylan stated "that employee satisfaction and customer orientation has a mid-level effect on creating a substantial organizational culture" ([98], p. 1203).

Moreover, studies in health care often only focus on nurses [30] or physicians [97] and not on the interprofessional team. The health care professionals often differ in their culture, which is a barrier for effective interprofessional teamwork [99-104]. Breaking down health care professional silos (see e.g. $[8,103])$ or rather working on a common culture helps to improve interprofessional teamwork as well as job satisfaction. Longitudinal intervention studies are needed to prove this assumption.

In order to consider German culture, we did not translate an existing instrument, but took an existing German instrument (the Corporate Culture Scale - Short Form (CCS-SF) by Jöns et al. [70]), adapted it to the interprofessional clinical context and validated it [72]. Although a range of instruments are globally accessible, to the best of our knowledge the HCQ is the first questionnaire specifically developed for measuring organizational or rather clinical culture in an interprofessional health care context in Germany. Instruments in health care often focus on selected aspects such as safety culture (e.g. [105]). HCQ focuses thereby on the main quality aspects, such as patient-, staff-, and quality-centeredness of clinics. Scott et al. [45] stated that there is no ideal instrument; they all have their limitations.

The study results confirm our recommendation to focus more on organizational aspects of the clinics such as structure, strategy and leadership in order to improve effectiveness and efficiency. It is known from several studies that good interprofessional teamwork and job satisfaction are essential preconditions for high quality care and clinical effectiveness [26, 35, 106, 107]. Ramanujam and Rousseau summarized this very appropriately: "The challenges are organizational and not just clinical" ([107]; p. 811) and described that thinking "organizationally has powerful implications for health care organizations" [p. 823], because the staff and the teams are embedded in an organization which impacts their behavior, the teamwork, etc. [94].

\section{Limitations and strengths}

The study has methodological limitations. The generalizability of the results for all in-patient medical rehabilitation clinics in Germany is limited because we only covered 15 clinics in southwest Germany, and the questionnaire return rate was below $50 \%$, which was stated as acceptable by Bungard and Jöns [108]. Yet, our rate of $42 \%$ is fairly good in comparison with other studies in health care, where the average return rate for employee surveys was between 30 and $50 \%$ [28, 109]. Due to the voluntary participation of the clinics as well as the clinic staff, selection effects are likely to have occurred. It can be assumed that motivated clinics and staff were more likely to participate. The representativeness of our sample remains an open issue, as we did not obtain background data about the staff in the clinics (e.g., team composition, gender and age).

The medium to high correlations of the constructs could be the result of overlapping constructs $[63,70,110]$ and of common-method bias [111]. We also rely on selfreported data, potentially giving rise to single-source bias. Furthermore, the study's design is cross-sectional and hence does not allow for a causal interpretation of the relationships found in the predictive model. Longitudinal or intervention studies should be conducted to examine the causality of the proposed relationships. Despite the low indicator reliability $(\leq .4)[79]$ of three items (see Table 5: items 'patient-oriented', 'quick decision making' and 'agreements'), we did not eliminate them from the model in the SEM because we wanted to retain the contents.

However, the study also possesses some specific strengths. It is a multi-center study, and it confirmed with a good model fit, a theory-based model designed on the basis of the IPO model. To our knowledge, no other study has been published on this issue in an interprofessional health care context. In general, few studies focus on organizational factors in health care organizations. Germany in particular is lacking in this field. The study therefore delivers results in a research field where empirical findings are rather rare [66]. The mediation of the effect of organizational behavior on job satisfaction through interprofessional teamwork in health care organizations has not been tested before. Further studies should investigate the constructs and their interdependence in a more differentiate manner.

\section{Conclusions}

With regard to practical implications of the results, managers of health care organizations are advised to increase their awareness concerning the importance of good organizational culture and interprofessional teamwork. Furthermore, the implementation of team development interventions can be recommended and should be supported. Any such intervention should be tailored to the needs of the teams, and further research should evaluate these interventions to find evidence-based best practices. The evaluation of these interventions should rely on a set of different assessment methods. It is desirable to put more weight on behavior, which might be assessed through observation and it would be interesting to consider additional economic and outcome parameters on the patient side (e.g., treatment success and patient satisfaction). In order to combine organizational, team and patient data, the multi-level-approaches are the state of the art. Our study results underpin the importance of investigating the characteristics and effects of working conditions in health care facilities more 
comprehensively. The study is a foundation for further longitudinal intervention studies and multi-level approaches.

\section{Additional file}

Additional file 1: The hospital culture questionnaire.

\section{Abbreviations}

AVE: Average variance extracted; CFI: Comparative Fit Index; CR: Critical ratio; df: Degree of freedom; FR: Factor reliability; IPS: Internal Participation Scale; IR: Indicator reliability; MAR: Missing at random; M.I.: Modification indices; M: Mean value; RMSEA: Root Mean Square Error of Approximation; SD: Standard deviations; SEM: Structural equation modeling; TLI: Tucker-Lewis index; $X^{2}$ : Chi-Squared value; $X^{2} / \mathrm{df}$ : Normed Chi-Squared value.

\section{Competing interests}

The authors declare that they have no competing interests.

\section{Authors' contribution}

MK defined the design of the study, collected the data, analysed and interpreted the data and prepared the first draft of the manuscript. MW contributed to the design, the data analysis, and the interpretation of the data. JB supported the application for the grant, supervised the study and the manuscript, and revised the manuscript. AG contributed to the interpretation of the results in the discussion section and revised the manuscript. All authors discussed the results, read and approved the final manuscript.

\section{Authors' information}

Dr. Mirjam Körner (MK) Department of Medical Psychology and Medical Sociology, Medical Faculty, University of Freiburg, Germany; Mail: mirjam.koerner@mps.uni-freiburg.de

Prof. Dr. Markus Wirtz, Department of Research Methods, Institute of Psychology, University of Education Freiburg, Germany; Mail: markus.wirtz@ph-freiburg.de

Prof. Dr. Dr. Jürgen Bengel, Department of Rehabilitation Psychology and Psychotherapy, Institute of Psychology, University of Freiburg, Germany; Mail: juergen.bengel@psychologie.uni-freiburg.de

Prof. Dr. Anja S. Göritz, Department of Occupational and Consumer Psychology, Institute of Psychology, Germany, Mail:

goeritz@psychologie.uni-freiburg.de

\section{Acknowledgements}

The study is part of the German grant program "Chronic illness and patient orientation" and is supported by the German Federal Ministry of Research and Education and the German Statutory Pension Insurance Scheme (Funding Number: 01GX0720, Funding Period: April 2008 to August 2011). We would like to thank all patients and health care professionals in the rehabilitation clinics who supported the study (AOK-Klinik Korbmattfelsenhof, AOK-Klinik Stoeckenhoefe, Asklepios Triberg, DAK-Haus Schwaben, Klinik Bad Herrenalb GmbH, Kliniken Dr. Voetisch, Kurpark-Klinik, Neurologisches Rehabilitationszentrum Quellenhof, Rehabilitationsklinik Birkenbuck, Rehabilitationsklinik Gloecklehof, Rehabilitationsklinik St. Landelin, Reha-Zentrum Todtmoos, Rheintalklinik, Rehabilitationsklinik Hoehenblick, Therapiezentrum Muenzesheim). The authors also acknowledge the research assistance of Anne-Kathrin Steger und Heike Ehrhardt.

\section{Author details}

${ }^{1}$ Medical Psychology and Medical Sociology, University of Freiburg, Hebelstr. 29, 79104 Freiburg, Germany. ${ }^{2}$ Department of Research Methods, Institute of Psychology, University of Education Freiburg, Kunzenweg 21, 79117 Freiburg, Germany. ${ }^{3}$ Department of Rehabilitation Psychology and Psychotherapy, Institute of Psychology, University of Freiburg, Engelbergerstr. 41, 79085 Freiburg, Germany. ${ }^{4}$ Department of Occupational and Consumer Psychology, Institute of Psychology, University of Freiburg, Engelbergerstr. 41, 79085 Freiburg, Germany.
Received: 23 June 2014 Accepted: 22 May 2015

Published online: 23 June 2015

\section{References}

1. Bridges DR, Davidson RA, Odegard PS, Maki IV, Tomkowiak J. Interprofessional collaboration: three best practice models of interprofessional education. Med Educ Online. 2011;16:6035.

2. Gerdes N, Zwingmann C, Jäckel WH. The system of rehabilitation in Germany. In: Jäckel W, Bengel J, Herdt J, editors. Research in Rehabilitation. Results from a Research Network in Southwest Germany. Stuttgart: Schattauer; 2006. p. 3-19.

3. Braithwaite J, Westbrook M, Nugus P, Greenfield D, Travaglia J, Runciman W, et al. A four-year, systems-wide intervention promoting interprofessional collaboration. BMC Health Serv Res. 2012;12:99.

4. Salas E, Sims DE, Burke CS. Is there a 'Big Five' in Teamwork? Small Gr Res. 2005;36:555-99.

5. Canadian Interprofessional Health Collaborative. A national interprofessional competency framework. http://www.cihc.ca/files/CIHC_IPCompetencies_ Feb1210.pdf

6. Xyrichis A, Lowton K. What fosters or prevents interprofessional teamworking in primary and community care? A literature review. Int J Nurs Stud. 2008;45:140-53.

7. Gibbon B, Watkins C, Barer D, Waters K, Davies S, Lightbody L, et al. Can staff attitudes to team working in stroke care be improved? J Adv Nurs. 2002;40:105-11.

8. World Health Organization. Framework for Action on Interprofessional Education \& Collaborative Practice. Health Professions Networks Nursing \& Midwifery, Human Resources for Health. [http://whqlibdoc.who.int/hq/2010/ WHO_HRH_HPN_10.3_eng.pdf]

9. McGrath JE. Social psychology, a brief introduction. New York: Holt, Rinehart and Winston; 1964

10. Gladstein DL. Groups in Context: A Model of Task Group Effectiveness. Admin Sci Quart. 1984;29:499-517.

11. Kauffeld S, Schulte E. Teams und ihre Entwicklung. In: Kauffeld S, editor. Arbeits-, Organisations- und Personalpsychologie. Für Bachelor. Berlin, Heidelberg: Springer Berlin Heidelberg; 2011. p. 143-60.

12. Körner M. Analysis and development of multiprofessional teams in medical rehabilitation. Teamanalyse und Teamentwicklung in multiprofessionellen Teams in der medizinischen Rehabilitation. GMS Psychosoc Med. 2008;5:Doc01.

13. Körner M. Teamanalyse und Teamentwicklung in der medizinischen Rehabilitation. Dissertation. Regensburg: Roderer; 2006. Rehabilitationswissenschaften, Rehabilitationspsychologie, Rehabilitationsmedizin, vol. 12.

14. Lemieux-Charles L, McGuire WL. What Do We Know about Health Care Team Effectiveness? A Review of the Literature. Med Care Res Rev. 2006;63:263-300.

15. Rv D, West MA. Teamwork, Teamdiagnose, Teamentwicklung. Göttingen: Hogrefe; 2005 [Praxis der Personalpsychologie, vol. 8].

16. Xyrichis A, Ream E. Teamwork: a concept analysis. J Adv Nurs. 2008;61:232-41.

17. Mathieu J, Maynard MT, Rapp T, Gilson L. Team Effectiveness 1997-2007: A Review of Recent Advancements and a Glimpse Into the Future. J Manage. 2008;34:410-76.

18. Mathieu JE, Heffner TS, Goodwin GF, Salas E, Cannon-Bowers JA. The influence of shared mental models on team process and performance. J Appl Psychol. 2000;85:273-83.

19. Bosch M, Faber MJ, Cruijsberg J, Voerman GE, Leatherman S, Grol RPTM, et al. Review Article: Effectiveness of Patient Care Teams and the Role of Clinical Expertise and Coordination. Med Care Res Rev. 2009;66:5-35.

20. Burtscher MJ, Manser T. Team mental models and their potential to improve teamwork and safety: A review and implications for future research in healthcare. Saf Sci. 2012;50:1344-54.

21. Kockert S, Schott T. Die Bedeutung von Organisationsmerkmalen für den Rehabilitationserfolg. Rehabilitation. 2011;19:30.e1.

22. Hartnell CA, Ou AY, Kinicki A. Organizational culture and organizationa effectiveness: A meta-analytic investigation of the competing values framework's theoretical suppositions. J Appl Psychol. 2011;96:677-94.

23. Clarke DJ. Achieving teamwork in stroke units: The contribution of opportunistic dialogue. J Interprof Care. 2010;24:285-97.

24. Sinclair LB, Lingard LA, Mohabeer RN. What's So Great About Rehabilitation Teams? An Ethnographic Study of Interprofessional Collaboration in a Rehabilitation Unit. Arch Phys Med Rehabil. 2009;90:1196-201. 
25. Aiken LH, Sloane DM, Bruyneel L, van den Heede K, Sermeus W. Nurses' reports of working conditions and hospital quality of care in 12 countries in Europe. Int J Nurs Stud. 2013;50:143-53.

26. Chang W, Ma J, Chiu H, Lin K, Lee P. Job satisfaction and perceptions of quality of patient care, collaboration and teamwork in acute care hospitals. J Adv Nurs. 2009;65:1946-55.

27. Kalisch BJ, Hyunhwa L, Rochman M. Nursing staff teamwork and job satisfaction. J Nurs Manag. 2010;18:938-47.

28. Körner M. Interprofessional teamwork in medical rehabilitation: a comparison of multidisciplinary and interdisciplinary team approach. Clin Rehabil. 2010;24:745-55.

29. Robbins SP, Coulter M. Management. 11th ed. Essex: Pearson Prentice Hall.

30. Tsai Y. Relationship between Organizational Culture, Leadership Behavior and Job Satisfaction. BMC Health Serv Res. 2011;11:98-106.

31. Schein EH. Organizational culture. Am Psychol. 1990;45:109-19.

32. Strasser DC, Smits SJ, Falconer JA, Herrin JS, Bowen SE. The influence of hospital culture on rehabilitation team functioning in VA hospitals. J Rehabil Res Dev. 2002;39:115-25.

33. Lund DB. Organizational culture and job satisfaction. J Bus Ind Mark. 2003;18:219

34. Tzeng H, Ketefian S, Redman RW. The relationship of nurses' assessment of organizational culture, job satisfaction, and patient satisfaction with nursing care. Int J Nurs Stud. 2002;39:79-84.

35. Brazil K, Wakefield DB, Cloutier MM, Tennen H, Hall CB. Organizational culture predicts job satisfaction and perceived clinical effectiveness in pediatric primary care practices. Health Care Manage Rev. 2010;35:365-71.

36. King TM, Muzaffar S, George $M$. The role of clinic culture in implementation of primary care interventions: the case of reach out and read. Acad Pediatr. 2009:9:40-6.

37. Shortell SM, O'Brien JL, Carman JM, Foster RW, Hughes EF, Boerstler H, et al. Assessing the impact of continuous quality improvement/total quality management: concept versus implementation. Health Serv Res. 1995;30:377-401

38. Wakefield BJ, Blegen MA, Uden-Holman T, Vaughn T, Chrischilles E, Wakefield DS. Organizational culture, continuous quality improvement, and medication administration error reporting. Am J Med Qual. 2001;16:128-34.

39. Jacobs R, Mannion R, Davies HTO, Harrison S, Konteh F, Walshe K. The relationship between organizational culture and performance in acute hospitals. Soc Sci Med. 2013;76:115-25.

40. Mannion R, Davies HTO, Marshall MN. Cultural characteristics of "high" and "low" performing hospitals. J Health Organ Manag. 2005;19:431-9.

41. Gifford BD, Zammuto RF, Goodman EA. The relationship between hospital unit culture and nurses' quality of work life. J Health Manage. 2002;47:13-25.

42. Dodek P, Cahill NE, Heyland DK. The Relationship Between Organizational Culture and Implementation of Clinical Practice Guidelines A Narrative Review. J Parenter Enteral Nutr. 2010;34:669-74.

43. Sieveking N, Bellet W, Marston RC. Employees' views of their work experience in private hospitals. Health Serv Manage Res. 1993;6:129-38.

44. Klingle RS, Burgoon M, Afifi W, Callister M. Rethinking how to measure organizational culture in the hospital setting. The Hospital Culture Scale. Eval Health Prof. 1995;18:166-86.

45. Scott T, Mannion R, Davies H, Marshall M. The quantitative measurement of organizational culture in health care: a review of the available instruments. Health Serv Res. 2003;38:923-45.

46. Stock RD, Reece D, Cesario L. Developing a Comprehensive Interdisciplinary Senior Healthcare Practice. J Am Geriatr Soc. 2004;52:2128-33.

47. Wagner EH, Bennett SM, Austin BT, Greene SM, Schaefer JK, Vonkorff M. Finding common ground: Patient-centeredness and evidence-based chronic illness care. J Altern Complement Med. 2005;11:S7.

48. Schaefer J, Davis C. Case management and the chronic care model: a multidisciplinary role. Lippincotts Case Manag. 2004;9:96-103.

49. Körner M, Wirtz MA. Development and psychometric properties of a scale for measuring internal participation from a patient and health care professional perspective. BMC Health Serv Res. 2013;13:374.

50. Thylefors I, Persson O, Hellström D. Team types, perceived efficiency and team climate in Swedish cross-professional teamwork. J Interprof Care. 2005;19:102-14.

51. Quaschning K, Körner M, Wirtz M. Analyzing the effects of shared decisionmaking, empathy and team interaction on patient satisfaction and treatment acceptance in medical rehabilitation using a structural equation modeling approach. Patient Educ Couns. 2013;91:167-75.
52. O'Leary KJ, Sehgal NL, Terrell G, Williams MV. Interdisciplinary teamwork in hospitals: A review and practical recommendations for improvement. J Hosp Med. 2012;7:48-54.

53. Manser T. Teamwork and patient safety in dynamic domains of healthcare: a review of the literature. Acta Anaesthesiol Scand. 2009;53:143-51.

54. Salas E, Gregory ME, King HB. Team training can enhance patient safety-the data, the challenge ahead. J Comm J Qual Patient Saf. 2011;37:339-40.

55. Körner M. Mental strain among staff at medical rehabilitation clinics in Germany. GMS Psychosoc Med. 2011;8.

56. Poulton BC, West MA. The determinants of effectiveness in primary health care teams. J Interprof Care. 1999;13:7-18.

57. Grumbach K, Bodenheimer T. Can health care teams improve primary care practice? JAMA. 2004;291:1246-51.

58. Pryor J. Co-ordination of patient care in inpatient rehabilitation. Clin Rehabil. 2003;17:341-6.

59. Judge T, Church A. Job satisfaction: Research and practice. In: Cooper C, Locke E, editors. Industrial and organizational psychology: Linking theory with practice. Oxford: Blackwell; 2000. p. 166-98.

60. Locke $E$. The nature and causes of job satisfaction. In: Dunnette M, editor. Handbook of industrial and organizational psychology. Chicago: Rand McNally; 1976. p. 1297-349.

61. Campion MA, Medsker GJ, Higgs AC. Relations between work group characteristics and effectiveness: Implications for designing effective work groups. Pers Psychol. 1993;46:823-50.

62. Campion MA, Papper EM, Medsker GJ. Relations between work team charakteristics and effectiveness: A replication and extension. Pers Psychol. 1996:49:429-52.

63. van Saane N, Sluiter JK, Verbeek J, Frings-Dresen MH. Reliability and validity of instruments measuring job satisfaction-a systematic review. Occup Med. 2003:53:191-200.

64. Kazanjian A, Green C, Wong J, Reid R. Effect of the hospital nursing environment on patient mortality: a systematic review. J Health Serv Res Policy. 2005;10:111-7.

65. Landy FJ. An Opponent Process Theory of Job Satisfaction. J Appl Psychol. 1978;63:533-47.

66. Antoni $C_{\text {, Hertel }} \mathrm{G}$. Team processes, their antecedents and consequences: Implications for different types of teamwork. Eur J Work Organ Psy. 2009;18:253-66.

67. Wagner EH. Chronic disease management: what will it take to improve care for chronic illness? Eff Clin Pract. 1998;1:2-4.

68. Wagner EH, Austin BT, Davis C, Hindmarsh M, Schaefer J, Bonomi A. Improving chronic illness care: translating evidence into action. Health Aff (Millwood). 2001;20:64-78.

69. World Medical Association. World Medical Association Declaration of Helsinki. Ethical principles for medical research involving human subjects. Bull World Health Organ. 2001;79:373-4.

70. Jöns I, Hodapp M, Weiss K: Kurzskala zur Erfassung der Unternehmenskultur. Mannheimer Beiträge zur Wirtschafts- und Organisationspsychologie 2005, 3:3-10. Mannheim: Universität Mannheim, Lehrstuhl für Wirtschafts- und Organisationspsychologie. [http://psydok.sulb.uni-saarland.de/volltexte/2006/ 690/pdf/2005-03].

71. Büssing A, Glaser J. Mitarbeiter- und Klientenorientierung im Gesundheitswesen. Z Arb Organ. 2003;47:222-8.

72. Fröhlich M. Die Klinikkultur in der medizinischen Rehabilitation. Masterarbeit: Albert-Ludwigs-Universität, Psychologie; 2013.

73. Valentine MA, Nembhard IM, Edmondson AC. Measuring Teamwork in Health Care Settings: A Review of Survey Instruments. Working Paper; 2012

74. Farin $E$, Meixner $K$, Follert $P$, Jäckel WH, Jacob A. Mitarbeiterzufriedenheit in Rehabilitationskliniken: Entwicklung des MiZu-Reha-Fragebogens und Anwendung in der Qualitätssicherung. Rehabilitation. 2002:41(4):258-67.

75. Schafer JL, Graham JW. Missing data: Our view of the state of the art. Psychol Methods. 2002;7:147-77.

76. Kline RB. Principles and practice of structural equation modeling. New York: Guilford Press; 2005. p. 59.

77. Bentler PM. Comparative fit indexes in structural models. Psychol Bull. 1990;107:238-46.

78. Fornell C, Larcker DF. Evaluating Structural Equation Models with Unobservable Variables and Measurement Error. J Mark Res. 1981;18:39-50.

79. Hair JF. Multivariate data analysis: a global perspective. Upper Saddle River: Prentice Hall; 2010.

80. Bollen KA. Structural equations with latent variables. New York: Wiley; 1989 
81. Kline RB. Promise and pitfalls of structural equation modeling in gifted research. In: Thompson B, Subotnik RF, editors. Methodologies for conducting research on giftedness. Washington, DC, US: American Psychological Association; 2010. p. 147-69.

82. Fornell C, Larcker DF. Structural Equation Models with Unobservable Variables and Measurement Error: Algebra and Statistics. J Mark Res. 1981;18:382-8

83. Curral LA, Forrester RH, Dawson JF, West MA. It's what you do and the way that you do it: Team task, team size, and innovation-related group processes. Eur J Work Organ Psy. 2001;10:187-204.

84. Porter COLH. Goal Orientation: Effects on Backing Up Behavior, Performance, Efficacy, and Commitment in Teams. J Appl Psychol. 2005;90:811-8

85. Stewart GL, Barrick MR. Team Structure and Performance: Assessing the Mediating Role of Intrateam Process and the Moderating Role of Task Type. Acad Manage J. 2000;43:135-48.

86. Schein EH. Unternehmenskultur: Ein Handbuch für Führungskräfte. Frankfurt: Campus-Verlag; 1995.

87. Jacobs E, Roodt G. Organisational culture of hospitals to predict turnove intentions of professional nurses: research. Health SA Gesondheid. 2008;13:63-78.

88. Brennan SE, Bosch M, Buchan H, Green SE. Measuring team factors thought to influence the success of quality improvement in primary care: a systematic review of instruments. Implement Sci. 2013;8:20.

89. Deneckere S, Euwema M, Lodewijckx C, Panella M, Mutsvari T, Sermeus W, et al. Better interprofessional teamwork, higher level of organized care, and lower risk of burnout in acute health care teams using care pathways: a cluster randomized controlled trial. Med Care. 2013:51:99-107.

90. Bleakley A, Boyden J, Hobbs A, Walsh L, Allard J. Improving teamwork climate in operating theatres: The shift from multiprofessionalism to interprofessionalism. J Interprof Care. 2006;20:461-70.

91. Reeves S, Zwarenstein M, Goldman J, Barr H, Freeth D, Koppel I, et al. The effectiveness of interprofessional education: Key findings from a new systematic review. J Interprof Care. 2010;24:230-41.

92. Benson A. Creating a culture to support patient safety. The contribution of a multidisciplinary team development programme to collaborative working. Teamorientierte Zusammenarbeit. Z Evid Fortbild Qual Gesundhwes. 2010;104:10-7.

93. Körner M, Bütof S, Müller C, Zimmermann L, Becker S, Bengel J: Interprofessional Teamwork and Team Interventions in Chronic Care: A Systamtic Review. J Interprof Care, accepted.

94. Bosch M, Dijkstra R, Wensing M, van der Weijden T, Grol R. Organizational culture, team climate and diabetes care in small office-based practices. BMC Health Serv Res. 2008;8:180

95. Meterko M, Mohr DC, Young GJ. Teamwork culture and patient satisfaction in hospitals. Med Care. 2004;42:492-8.

96. Ilgen DR, Hollenbeck JR, Johnson M, Jundt D. Teams in Organizations: From Input-Process-Output Models to IMOI Models. Annu Rev Psychol. 2005;56:517-43.

97. Zazzali JL, Alexander JA, Shortell SM, Burns LR. Organizational Culture and Physician Satisfaction with Dimensions of Group Practice. Health Serv Res. 2007:42:1150-76.

98. Aydin B, Ceylan A. What is the joint effect of employee satisfaction and customer orientation on the organizational culture in metalworking manufacturing? Int J Hum Resour Man. 2011;22:1203-15.

99. Braithwaite J. Between-group behaviour in health care: gaps, edges, boundaries, disconnections, weak ties, spaces and holes. A systematic review. BMC Health Serv Res. 2010;10:330.

100. Delva D, Jamieson M, Lemieux M. Team effectiveness in academic primary health care teams. J Interprof Care. 2008;22:598-611.

101. Hall P. Interprofessional teamwork: Professional cultures as barriers J Interprof Care. 2005;19:188-96.

102. Körner M, Göritz A, Bengel J. Healthcare professionals' evaluation of interprofessional teamwork and job satisfaction. Evaluation of teamwork and job satisfaction. Int J Health Prof. 2014;1:5-12.

103. Margalit R, Thompson S, Visovsky C, Geske J, Collier D, Birk T, et al. From professional silos to interprofessional education: campuswide focus on quality of care. Qual Manage Health Care. 2009;18:165-73.

104. Pecukonis E, Doyle O, Bliss DL. Reducing barriers to interprofessional training: Promoting interprofessional cultural competence. J Interprof Care. 2008;22:417-28
105. Hammer A, Ernstmann N, Ommen O, Wirtz M, Manser T, Pfeiffer $Y$, et al. Psychometric properties of the Hospital Survey on Patient Safety Culture for hospital management (HSOPS_M). BMC Health Serv Res. 2011;11:165.

106. Scott T, Mannion R, Davies HTO, Marshall MN. Implementing culture change in health care: theory and practice. Int J Qual Health Care. 2003;15:111-8.

107. Ramanujam R, Rousseau DM. The challenges are organizational not just clinical. J Organiz Behav. 2006;27:811-27.

108. Bungard W, Jöns I. Mitarbeiterbefragung: Ein Instrument des Innovations- und Qualitätsmanagements. Weinheim: Psychologie Verlags Union; 1997 [Arbeits- und Organisationspsychologie in Forschung und Praxis, Band 10].

109. Milch W, Ernst R, Laubach W. Kooperation und Arbeitszufriedenheit im pflegerisch-ärztlichen Team. Eine Analyse pflegerischer Bewertungen in der Psychiatrie. Psychiatr Prax 1999;26:122-127.

110. Ginevičius R, Vaitkūnaite V. Analysis of organizational culture dimensions impacting performance. J Bus Econ Manag. 2006;7:201-11.

111. Podsakoff PM, Mackenzie SB, Lee J, Podsakoff NP. Common method biases in behavioral research: A critical review of the literature and recommended remedies. J Appl Psychol. 2003;88:879-903.

\section{Submit your next manuscript to BioMed Central and take full advantage of:}

- Convenient online submission

- Thorough peer review

- No space constraints or color figure charges

- Immediate publication on acceptance

- Inclusion in PubMed, CAS, Scopus and Google Scholar

- Research which is freely available for redistribution 